\title{
Analysis of maxillary anterior teeth proportion in relationship with lower facial height and malocclusion
}

\author{
Rajesh Gyawali, Varun Pratap Singh \\ Shri Jagdishprasad Jhabarmal Tibrewala University, Jhunjhunu, Rajasthan, India
}

\begin{tabular}{l}
\hline Correspondence \\
Dr. Rajesh Gyawali \\
Phd Scholar, \\
Shri Jagdishprasad Jhabarmal \\
Tibrewala University, \\
Jhunjhunu, Rajasthan, India \\
Email: \\
gyawalirajesh@gmail.com \\
ORCID ID: \\
http://orcid.org/0000-0003-0561-6018
\end{tabular}

DOI: http://dx.doi.org/10.3126/ jemsn.v13i2.16717

Article received: $26^{\text {th }}$ Nov 2016 Article accepted: $4^{\text {th }}$ May 2017

\begin{abstract}
Background \& Objectives: Maxillary anterior tooth to tooth proportion has a special value in dental esthetics. This study aimed to assess the apparent proportion of maxillary anteriors and possible association with lower anterior facial height and malocclusion type. Materials \& Methods: One-hundred and sixty samples with well aligned maxillary dentition were selected and the lower anterior facial height was measured with digital caliper. Molar relationship was examined and intraoral frontal photograph was taken for digital measurement of tooth proportion. The ratio of maxillary canine to lateral and lateral to central incisors were measured and compared between gender and the sides. These ratios were further compared among various malocclusion type using ANOVA and its association with lower anterior facial height was evaluated with Pearson's correlation. Results: Most of the samples had Class I molar relationship (70\%) followed by Class II (23\%) and Class III (7\%). The mean lower anterior facial height was $62.82 \mathrm{~mm}$ and ratio of maxillary lateral to central incisor and canine to lateral incisor was 0.68 and 0.76 respectively. No statistically significant difference was found when the ratio was compared between the gender and the sides. These ratios were statistically different from the golden ratio and has no significant correlation with lower anterior facial height. These mean ratios were also found similar across the malocclusion type.

Conclusion: Ratio of apparent dimension of maxillary canine to lateral incisor and lateral to central incisor was different from the golden ratio and showed no association with lower anterior facial height and malocclusion type.
\end{abstract}

Key words: Golden proportion; malocclusion; lower anterior facial height; tooth proportion

Citation: Gyawali R, Singh VP. Analysis of maxillary anterior teeth proportion in relationship with lower facial height and malocclusion. JCMS Nepal. 2017;13(2):262-7.

\section{INTRODUCTION}

Orthodontic treatment aims to improve function, balance and esthetics among various structural components of the stomatognathic system, however, enhancement of the facial and dental esthetics is the main reason for patients considering the orthodontic consultation. Beautiful and attractive face has an added advantage in the life of an individual starting from the birth. ${ }^{1}$ Smile is the most important aspect assessed by the perceiver during any face to face interaction and maxillary anteriors are the prominent and dominant teeth appreciated during smile. Hence, orthodontists or the esthetic dentists have been reeling on size, shape, proportion of maxillary anterior teeth with the aim of enhancing the smile esthetics which further contributes to the overall beauty of an individual.

Golden proportion is a constant ratio of $1.618: 1$ which is widely observed in nature and has been found to be pleasing to the human eyes. With the introduction of golden proportion in dentistry, ${ }^{2}$ it was proposed in estimating the apparent dimension of maxillary anterior teeth when viewed from the 
front. $^{3}$ However, the literature witnesses a continuous wide debate regarding the ideal perceived tooth to tooth ratio for enhancing esthetic smile. ${ }^{4-7}$ This ratio has been found to vary with race, gender, and ethnicity. ${ }^{8-10}$ In considering the factors affecting this perceived esthetic ratio, the vertical dimension of the face and malocclusion type has been given less importance.

Hence, this study was carried out with the aim of assessing the apparent tooth to tooth proportion of maxillary anterior region and finding out the possible association with lower anterior facial height and malocclusion type.

\section{MATERIALS AND METHODS}

This study was started after obtaining the ethical clearance from Nepal Health Research Council. For the sample size calculation, the assumptions made were: confidence level of $95 \%$, significance level of 0.05 , statistical power of $95 \%$, and smallest relevant difference of $0.01 \mathrm{~mm}$ and the estimated standard deviation of 0.17 . The standardized difference was calculated as the ratio of smallest relevant difference to the estimated standard deviation which was 0.58. Using Altmann nomogram, the sample size would be approximately 150 . Hence, 160 samples were chosen for this study with equal number of males and females.

The study was conducted in the Department of Orthodontics, B.P.Koirala Institute of Health Sciences, Dharan, Nepal. All the patients with well aligned maxillary anteriors and all the permanent teeth present till second molars were included. However, patients with prior orthodontic or restorative treatment of maxillary anteriors, attrited or fractured anteriors, gingival inflammation or recession involving the labial surface were excluded.

After obtaining the informed consent from the participants, the lower anterior facial height (LAFH) was measured from subnasale to the lower border of the soft tissue chin with the help of digital Vernier caliper with the accuracy upto $0.01 \mathrm{~mm}$ (Mitutoyo: CD-8" CS, Japan). Intra-oral examination was done to find out the molar relationship. Molar relationship was classified into Class I, Class II and Class III. Further, intra-oral frontal photograph was made with Nikon D5100 camera with the patient lying comfortably in the dental chair and the soft tissues retracted with the two photographic plastic retractors. During the photography, patient's head was kept straight with the coronal plane perpendicular to the long axis of
Table 1: Parameters measured with Image J software:

MD13 Mesiodistal dimension of maxillary right canine

MD12 Mesiodistal dimension of maxillary right lateral incisor

MD11 Mesiodistal dimension of maxillary right central incisor

MD21 Mesiodistal dimension of maxillary left central incisor

MD22 Mesiodistal dimension of maxillary left lateral incisor

MD23 Mesiodistal dimension of maxillary left canine

R1 Ratio of mesiodistal dimension of maxillary lateral to central incisor

R2 Ratio of mesiodistal dimension of maxillary canine to lateral incisor

the lens of camera to avoid the effect of rotation on the photographic dimension. ${ }^{11}$

The photograph obtained was transferred to a computer and the measurements made with the Image J (1.49) software (freely available at http:// imagej.nih.gov/ij/) (Table 1). Data obtained from the measurements were uploaded in Microsoft Excel 2013 and further to SPSS version 20 for statistical analysis. All the measurements were made by a single investigator (RG).

\section{RESULTS}

This study involved participation of 160 subjects ( 80 in each sex). The mean age of the sample was $21.51 \pm 2.78$ years with a range of 12 to 25 years. Most of them had Class I molar relationship followed by Class II and Class III (Figure 1). The distribution of the ratio of the apparent mesiodistal tooth width was evaluated with Shapiro Wilk test. The $p$-values were above the level of 0.05 indicating the normal distribution of these variables.

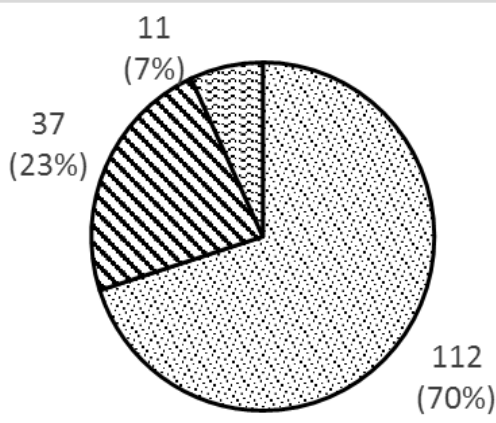

\section{Class | $\mathbf{\Delta C l a s s ~ | | ~}$ 图 Class |||}

Figure 1. Distribution of the molar relationship 
Table 2. Intraclass correlation coefficient of remeasured parameters.

$\begin{array}{lllllllll}\text { Re-measured variables } & \text { LAFH } & \text { MD13 } & \text { MD 12 } & \text { MD 11 } & \text { MD 21 } & \text { MD 22 } & \text { MD 23 } \\ \text { ICC } & 0.987 & 0.916 & 0.917 & 0.932 & 0.902 & 0.967 & 0.950\end{array}$

ICC: Intraclass correlation coefficient; MD: Apparent Mesiodistal dimension; LAFH: Lower anterior facial height

Table 3. Paired t-test for comparison of Mean R1 and R2 between left and right side

\begin{tabular}{lllllllll} 
Measurements & \multicolumn{2}{l}{ Right side } & \multicolumn{2}{l}{ Left side } & Mean Diff & $95 \%$ CI & t & P value \\
& Mean & SD & Mean & SD & & & \\
Mean R1 & 0.681 & 0.067 & 0.677 & 0.083 & -0.003 & -0.009 to 0.016 & 0.582 & 0.561 \\
Mean R2 & 0.757 & 0.141 & 0.756 & 0.149 & -0.034 & 0.022 to -0.024 & 0.097 & 0.923
\end{tabular}

Table 4. LAFH, mean $R 1$ and mean $R 2$ comparison between male and female

\begin{tabular}{|c|c|c|c|c|c|c|c|}
\hline \multirow[t]{2}{*}{ Measurements } & \multicolumn{2}{|l|}{ Male } & \multicolumn{2}{|l|}{ Female } & \multirow[t]{2}{*}{ Mean Diff } & \multirow[t]{2}{*}{$95 \% \mathrm{CI}$} & \multirow[t]{2}{*}{$P$ value } \\
\hline & Mean & $\mathrm{SD}$ & Mean & $\mathrm{SD}$ & & & \\
\hline LAFH & 64.60 & 5.69 & 61.04 & 4.79 & 3.56 & 1.92 to 5.20 & 0.000 \\
\hline Mean R1 & 0.68 & 0.07 & 0.68 & 0.06 & -0.003 & -0.024 to 0.016 & 0.708 \\
\hline Mean R2 & 0.77 & 0.12 & 0.74 & 0.13 & -0.034 & 0.019 to -0.004 & 0.078 \\
\hline
\end{tabular}

Two weeks later, $32(20 \%)$ samples were selected randomly and the measurements of LAFH, and apparent mesiodistal width of maxillary anteriors were remade. The ICC (Intra-class correlation coefficient) of these measurements confirmed excellent intrarater reliability (Table 2). The reliability of reassessment of malocclusion class was confirmed by Kappa which showed good reliability $(\mathrm{k}=0.844)$.

The ratio between lateral to central incisor and canine to lateral incisor was compared between right and left side. The paired t-test showed no significant difference between the right and left side for both R1 and R2 (Table 3).Hence, mean of right and left side was calculated and subjected to further statistical analysis. The mean R1 and R2 were 0.68 \pm 0.06 and $0.76 \pm 0.12$ respectively.

LAFH, Mean R1 and R2 were compared between the two sexes using independent sample t-test and no statistically significant differences were found between the two sexes in R1 and R2. However, lower anterior facial height showed a significant difference between male and female (Table 4).

One sample t-test was done to check whether the R1 and R2 was statistically different from the ideal golden ratio i.e. 0.618 , and the result showed that the sample ratio was significantly different from the golden ratio, $\mathrm{t}(159)=12.084, \mathrm{p}=0.000$ and $\mathrm{t}(159)$ $=13.987, \mathrm{p}=0.000$ respectively.

Further, the correlation of R1 and R2 was assessed with lower anterior facial height. The correlation coefficient was -0.004 and 0.000 for R1 and R2 respectively showing negligible correlation. The scatterplot also proves no linear relationship (Figure 2 and 3 ).

One-way ANOVA was performed to check whether R1 and R2 vary across various groups of malocclusion. It was found that there was no statistically significant difference in the ratios among various malocclusion types (Table 5).

\section{DISCUSSION}

This study was undertaken with the aim of assessing the microesthetic features of maxillary anterior dentition and finding its association with lower anterior facial height and malocclusion type. Most of the samples had Class I molar relation followed by Class II and Class III. The epidemiological studies exploring malocclusion in Nepalese also found increased prevalence of Class I 
Table 5. ANOVA for comparison of $R 1$ and $R 2$ across the malocclusion types

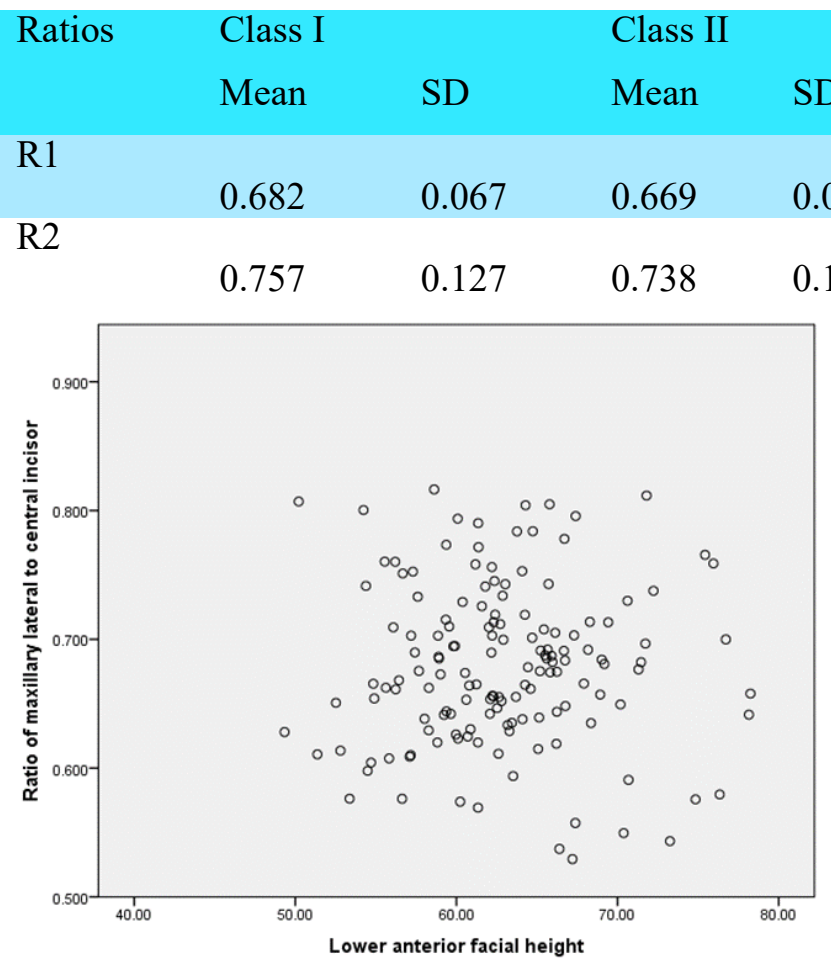

Figure 2. Scatterplot demonstrating the relationship between lower anterior facial height and ratio of maxillary lateral to central incisor

\begin{tabular}{|c|c|c|c|}
\hline Class III & & $\mathrm{F}$ & $\mathrm{P}$ valu \\
\hline Mean & SD & & \\
\hline 0.682 & 0.068 & 0.524 & 0.593 \\
\hline 0.805 & 0.111 & 1.246 & 0.29 \\
\hline
\end{tabular}

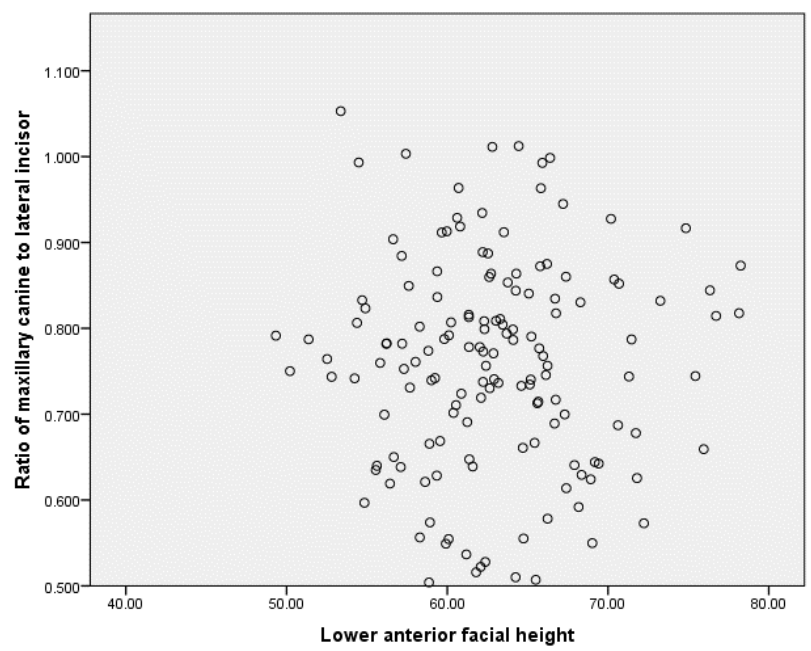

Figure 3. Scatterplot demonstrating the relationship between lower anterior facial height and ratio of maxillary canine to lateral incisor

Table 6. $\mathrm{R} 1$ and $\mathrm{R} 2$ across various population

\begin{tabular}{|c|c|c|c|c|c|}
\hline Study & Population & R1 & & \multicolumn{2}{|l|}{$\mathbf{R 2}$} \\
\hline \multirow[t]{2}{*}{ Sandeep et $\mathrm{al}^{29}$} & \multirow{2}{*}{ South Indians } & \multicolumn{2}{|l|}{0.67 (male) } & \multicolumn{2}{|c|}{0.744 (male) } \\
\hline & & 0.703 (female & & \multicolumn{2}{|c|}{0.714 (female) } \\
\hline \multirow{2}{*}{ Hasanreisoglu et $\mathrm{al}^{30}$} & \multirow{2}{*}{ Turkish } & 0.66 (male) & & \multicolumn{2}{|l|}{0.80 (male) } \\
\hline & & 0.65 (female) & & \multicolumn{2}{|c|}{0.79 (female) } \\
\hline Condon et $\mathrm{al}^{17}$ & Irish & & .65 & & 0.89 \\
\hline \multirow[t]{2}{*}{ Agrawal et a $1^{27}$} & Indians & & .72 & & 0.84 \\
\hline & Chinese & & 738 & & 0.748 \\
\hline \multirow[t]{2}{*}{ Al-Marzok et al ${ }^{6}$} & Indian & & 710 & & 0.801 \\
\hline & Malay & & 744 & & 0.786 \\
\hline Kanaparthy et al ${ }^{10}$ & Saudi & 0.689 (male) & 0.626 (female) & 0.60 (male) & 0.550 (female) \\
\hline $\begin{array}{l}\text { Gyawali and Singh (this } \\
\text { study) }\end{array}$ & Nepalese & 0.68 (male) & 0.68 (female) & $0.77(\mathrm{ma}$ & e) 0.74 (female) \\
\hline
\end{tabular}


malocclusion followed by Class II and III; ${ }^{12-15}$ and hence it was quite common for such distribution in this study sample.

No significant difference in R1 and R2 was found when compared between the two sides and the gender. This is similar to the results obtained in Iranian students, ${ }^{4,} 16$ and Irish students. ${ }^{17}$ Several odontometric studies also suggested that tooth size don't vary between the sides. ${ }^{18-20}$ Similarly, ethnicity has been found to play no role in the tooth proportion. ${ }^{6}$ This study showed that males tend to have long lower facial height as compared to female which is supported by similar findings in Turkish ${ }^{21}$ White, ${ }^{22}$ Iraqis, ${ }^{23}$ Central Indians,${ }^{24}$ North Indians ${ }^{25}$ and South Indians. ${ }^{26}$

Golden ratio has been widely studied in dentistry and it is believed that this ratio exists between maxillary lateral to central incisor and canine to lateral incisor. The ratios $-\mathrm{R} 1$ and R2in our sample deviated significantly from the well-established golden ratio. Several studies also revealed the nonexistence of golden proportion in the tooth to tooth ratio of maxillary anterior teeth (table 6). ${ }^{4,6,27}$ ${ }^{31}$ Photographic study in Iranian students confirmed presence of golden ratio in R1 and R2 in only $25 \%$ and $2.1 \%$ of the samples respectively. ${ }^{16}$ Similarly, golden proportion existed only in 14 to $25 \%$ of dental students of Asian origin. ${ }^{8}$ However, Kanaparthy et al found that R2 in male and R1 in female correspond to the golden ratio whereas $\mathrm{R} 1$ in male and $\mathrm{R} 2$ in female do not. ${ }^{10}$ Golden proportion was found only in R1 in $17 \%$ of samples from University of North Carolina. ${ }^{32}$ Similarly, Iranian dental students showed existence of golden proportion only in R1 but not in R2. ${ }^{17}$

The mesiodistal dimension of maxillary anteriors has been positively correlated with the bizygomatic width, inter-pupillary distance, inter-alar distance, inter-canthaldistance, intercommisural width. Further, a ratio was proposed to calculate the height of maxillary central incisor from the facial height. ${ }^{33}$ In this study, the absolute dimensions of individual teeth were not considered but rather the tooth-to tooth ratio was analyzed. The result showed negligible correlation of R1 and R2 with lower anterior facial height. Besides, the R1 and R2 across various malocclusion group did not show any significant difference.

\section{CONCLUSION}

- The ratio of maxillary lateral to central incisor and canine to lateral incisor was found to be 0.68 and 0.76 respectively with no statistically significant difference between the sides and sex.

- The lower anterior facial height in male (mean of $64.60 \mathrm{~mm} \pm 5.69$ ) was statistically greater than female (mean of $61.04 \pm 4.79$ ).

- The ratios R1 and R2 do not correspond with the golden ratio and has no association with lower anterior facial height and malocclusion type.

\section{REFERENCES}

1. Bull R, Rumsey N. The social psychology of facial appearance: Springer-Verlag Publishing; 1988.http:// dx.doi.org/10.1007/978-1-4612-3782-2 7

2. Lombardi RE. The principles of visual perception and their clinical application to denture esthetics. The Journal of prosthetic dentistry. 1973;29(4):358-82. http:// dx.doi.org/10.1016/s0022-3913(73)80013-7

3. Levin EI. Dental esthetics and the golden proportion. The Journal of prosthetic dentistry. 1978;40(3):244-52. http:// dx.doi.org/10.1016/0022-3913(78)90028-8

4. Mahshid M, Khoshvaghti A, Varshosaz M, Vallaei N. Evaluation of "golden proportion" in individuals with an esthetic smile. Journal of Esthetic and Restorative Dentistry. 2004;16(3):185-92. http://dx.doi.org/10.1111/ j.1708-8240.2004.tb00032.x

5. Bukhary S, Gill D, Tredwin C, Moles D. The influence of varying maxillary lateral incisor dimensions on perceived smile aesthetics. British dental journal. 2007;203(12):68793. http://dx.doi.org/10.1038/bdj.2007.1110

6. Al-Marzok MI, Majeed KRA, Ibrahim IK. Evaluation of maxillary anterior teeth and their relation to the golden proportion in malaysian population. BMC oral health. 2013;13(1):9. http://dx.doi.org/10.1186/1472-6831-13-9

7. Snow SR. Esthetic smile analysis of maxillary anterior tooth width: the golden percentage. Journal of Esthetic and Restorative Dentistry. 1999;11(4):177-84. http:// dx.doi.org/10.1111/j.1708-8240.1999.tb00397.x

8. Murthy BS, Ramani N. Evaluation of natural smile: Golden proportion, RED or Golden percentage. JCD. 2008;11 (1):16. http://dx.doi.org/10.4103/0972-0707.43413

9. Shah SA, Naqash TA, Malik BR. Effect of Golden Proportion Evaluation in Cosmetic Dental Restoration of Maxillary Anterior Teeth in Kashmiri Population: A Research. History. 2014;10(38):58-61.

10. Kanaparthy A, Kanaparthy R, Boreak N, Aslami R. Evaluation of widths of maxillary anterior teeth and their relation to the golden proportion in the southwestern part of Saudi Arabia. Journal of Research in Medical and Dental Science. 2016;4(2):83-86. http://dx.doi.org/10.5455/ jrmds. 2016422

11. Gyawali R, Pokharel PR, Giri J. Effect of Subject Rotation on Assessment of Esthetic Dental Ratios: A Simulation Study. International journal of dentistry. 2016;2016. http:// dx.doi.org/10.1155/2016/3957806

12. Shrestha BK, Yadav R, Gyawali R, Gupta S. Prevalence of malocclusion among medical students in Institute of medicine, Nepal: a Preliminary report. Orthodontic Orthod J Nep. 2013;1(1):24-27. http://dx.doi.org/10.3126/ ojn.v1i1.9362

13. Shrestha BK, Yadav R, Basel P. Prevalence of malocclusion among high school students in Kathmandu valley. Orthod J Nep. 2012;2:1

14. Sharma JN. Epidemiology of malocclusions and assessment of orthodontic treatment need for the population of eastern Nepal. World journal of orthodontics .2009;10 (4). PMID: 20072748. 
15. Singh VP, Sharma A. Epidemiology of Malocclusion and Assessment of Orthodontic Treatment Need for Nepalese Children. International Scholarly Research Notices. 2014;2014. http://dx.doi.org/10.1155/2014/768357

16. Azimi M, Dinparvar M, Teimourian H, Farhadian M. Evaluating Recurring Esthetic Dental Proportion (RED) and Golden Proportion in Natural Dentition. Avicenna Journal of Dental Research. 2016. http:// dx.doi.org/10.17795/ajdr-30267

17. Condon M, Bready M, Quinn, F, O'Connell BC, Houston FJ, O'Sullivan Maxillary anterior tooth dimensions and proportions in an Irish young adult population. Journal of oral rehabilitation. 2011;38(7):50108. http://dx.doi.org/10.1111/j.1365-2842.2010.02181.x

18. Hashim H, Murshid Z. Mesiodistal tooth width in a Saudi population sample comparing right and left sides. Part 2 Egyptian dental journal. 1993;39(1):347-50. PMID: 8299533.

19. Garn SM, Lewis AB, Kerewsky RS. The meaning of bilateral asymmetry in the permanent dentition. The Angle orthodontist. 1966;36(1):55-62 .

20. Bishara SE, Garcia AF, Jakobsen JR, Fahl JA. Mesiodistal crown dimensions in Mexico and the United States. The Angle orthodontist. 1986;56(4):315-23. PMID: 3466559.

21. Uysal T, Yagci A, Basciftci FA, Sisman Y. Standards of soft tissue Arnett analysis for surgical planning in Turkish adults. The European Journal of Orthodontics. 2009;31 (4):449-56. http://dx.doi.org/10.1093/ejo/cjn123

22. Arnett GW, Jelic JS, Kim J, Cummings DR, Beress A, Worley CM Jr et al. Soft tissue cephalometric analysis: diagnosis and treatment planning of dentofacial deformity. American Journal of Orthodontics and Dentofacial Orthopedics. 1999;116(3):239-53. PMID: 10474095.

23. Kadhom ZM, Al-Janabi MF. Soft-tissue cephalometric norms for a sample of Iraqi adults with class I normal occlusion in natural head position. J Bagh Coll Dentistry. 2011;23(3):160-66.

24. Chhajed S, Kodumuru S, Singh G, Arun AV, Cholleti SK, Kotharet S. Facial Soft Tissue Cephalometric Norms in a Central Indian Ethnic Population. The Journal of Indian Orthodontic Society. 2014;48(1):7. http:// dx.doi.org/10.5005/jp-journals-10021-1211

25. Upadhyay JS, Maheshwari S, Verma SK, Zahid SN. Soft tissue cephalometric analysis applied to regional Indian population. National journal of maxillofacial surgery. 2013;4(2):159. 5950.127644

26. Kalha AS, Latif A, Govardhan S. Soft-tissue cephalometric norms in a South Indian ethnic population. American Journal of Orthodontics and Dentofacial Orthopedics. 2008;133(6):876-81. http://dx.doi.org/10.1016/ j.ajodo.2006.05.043

27. Agrawal VS, Kapoor S, Bhesania D, Shah C. Comparative photographic evaluation of various geometric and mathematical proportions of maxillary anterior teeth: A clinical study. Indian Journal of Dental Research. 2016;27 (1):32. http://dx.doi.org/10.4103/0970-9290.179811

28. Zhao Q, Li N, Cao J. Morphological features of maxillary anterior teeth in a sample of Chinese population. HOMOJournal of Comparative Human Biology. 2015;66(5):44854. http://dx.doi.org/10.1016/j.jchb.2015.06.001

29. Sandeep N, Satwalekar P, Srinivas S, Reddy CS, Reddy GR, Reddy BA. An Analysis of Maxillary Anterior Teeth Dimensions for the Existence of Golden Proportion: Clinical Study. JIOH. 2015;7(9):18. PMID: 26435610.

30. Hasanreisoglu U, Berksun S, Aras K, Arslan I. An analysis of maxillary anterior teeth: facial and dental proportions. The Journal of prosthetic dentistry. 2005;94(6):530-38 http://dx.doi.org/10.1016/j.prosdent.2005.10.007

31. Parnia F, Hafezqoran A, Mahboub F, Moslehifard E, Koodaryan R, Moteyagheni R, Salehsaber F. Proportions of maxillary anterior teeth relative to each other and to golden standard in tabriz dental faculty students. Journal of dental research, dental clinics, dental prospects. 2011;4(3):83-86. http://dx.doi.org/10.5681/joddd.2010.021

32. Preston JD. The golden proportion revisited. Journal of Esthetic and Restorative Dentistry. 1993;5(6):247-51. http://dx.doi.org/10.1111/j.1708-8240.1993.tb00788.x.

33. Radia S, Sherriff M, McDonald F, Naini FB. Relationship between maxillary central incisor proportions and facial proportions. The Journal of prosthetic dentistry. 2016. http://dx.doi.org/10.1016/j.prosdent.2015.10.019. 